\title{
Senior Editor's Note
}

With this issue, ILWCH introduces a number of changes and new features. To start, this is the first issue published with our new host institution-the Harry Van Arsdale Jr. Center for Labor Studies at the State University of New York's (SUNY) Empire State College. For the last five years ILWCH thrived thanks to the support of a consortium of Rutgers University administrators-the Dean of the School of Arts and Sciences, the Office of the Vice President of Academic Affairs and the Dean of the School of Labor and Management Studies. We were located, quite appropriately, at the Rutgers School of Labor and Management Studies and we would like to especially thank its current dean, Susan J. Schurman, her predecessor, David L. Finegold, and Labor Studies department chair, Adrienne Eaton. The resources provided by the university enabled ILWCH to formalize its editorial and production processes in ways that facilitated an unprecedented expansion of the journal's international content and readership. During this period, we increased our distribution to a wider range of countries and expanded our online access. We owe Rutgers a tremendous debt of gratitude for supporting us during these years.

We would also like to take this opportunity to express our gratitude to Peter Winn, who recently stepped down from his position as a senior editor. Peter has devoted much of his time and energy in recent years to making ILWCH the rigorous and regionally diverse journal that it is and we thank him for his important contributions. He will remain on the editorial board and we look forward to continuing to work with him in that capacity. With this issue, we welcome a new senior editor, Prasannan Parthasarathi, a historian of South Asian labor based at Boston College.

The past five years are also notable for the increased support offered by our publisher, Cambridge University Press (CUP). CUP has helped the journal benefit from the growing interest in global labor history by promoting us through their international network of more than eighty scholarly journals. With Cambridge's backing, ILWCH has been able to integrate our colleague, Dr. Marcel van der Linden, Research Director of the International Institute of Social History, Amsterdam, as Associate Editor. His involvement has enhanced our ability to engage with scholars from around the world and bring deeper and broader coverage of the Global South to our readership.

Our new home- the Van Arsdale Center, located in the TriBeCa neighborhood of New York City-is an institution that serves nontraditional students, many of whom are working adults and union members. Empire State College (ESC) is a working people's school, part of the long tradition of labor education, and we expect that it will bring ILWCH into closer contact with the vast and 
diverse workforce of the city of New York. We thank Michael Merrill, Dean of the Center, for all his work to bring the journal to ESC and welcome Ms. Audrey Campbell, of the Van Arsdale Center's staff, to her new role as ILWCH's Managing Editor. This move was the result of the generous support of Dean Merrill and the president of Empire State College, Merodie A. Hancock. We look forward to a future of fruitful collaboration as we develop in new directions. We plan to publish a special issue on Labor Education internationally in honor of this move.

This issue of $I L W C H$ is just the first to take advantage of Cambridge University Press's new online supplemental materials feature, which we hope will augment and further enrich the content of the print edition. Subscribers and those who purchase \#84 online will have access to photos we were unable to include in the hard copy due to space constraints and will also be able to see color versions of photos published here in black and white. In the future, we will have the opportunity to include audio files (music, interviews, performances, etc.), video clips, and links to pertinent web sites. This new web presence will also enable ILWCH to host interactive online debates, keep our readers apprised of the large (and growing!) number of nationally and regionally-based labor history societies and conferences, and post conference notes and reports from the field in "real time." We wish to thank Cambridge for offering these services that will enable ILWCH to become more accessible and current.

This issue, ILWCH 84, follows and expands upon our traditional thematic focus by including articles on two significant topics: the social and cultural impact of deindustrialization and the social history of the Iranian oil industry. Both are timely and should be of interest to readers around the globe. The issue's first section, "Crumbling Cultures: Deindustrialization, Class and Memory," brings an important cultural perspective to the study of deindustrialization in the United Kingdom, Ukraine and the US. It comprises eight papers-six case studies, an introductory essay and a concluding commentary. The editors of this section-Timothy Strangleman (University of Kent, UK), Sherry Lee Linkon (Georgetown University) and James Rhodes (University of Manchester, UK) - have assembled papers that raise new questions inspired by several decades of deindustrialization and economic collapse in North America and Europe. The authors reconstruct multi-layered experiences of workers and working- class communities that have lived or are currently living through job loss and economic crises. The papers in this section take an interdisciplinary approach to rethinking the ways that industrial work and its disappearance affect identity and memory, both individual and collective. These memories-celebratory and grief-stricken-inform the contemporary politics and cultural productions of formerly industrialized communities. All the authors concern themselves with the cultural impact of deindustrialization and, with this optic, bring new and deeper understandings of the process and its continuing impact. Their articles recapture the "lived experience" of seeing one's work disappear, probe the ways that workers think back upon the past, 
and analyze the ways that successive generations, for whom collapsed factories and mines are the only reality, process their relationship to the lost world of their forebears. The editors situate the papers within the scholarly literature on deindustrialization, describe the evolution of "deindustrial studies" through the cultural lens, and contend that deindustrialization is transformative on a cultural as well as a material level. They argue that sources such as art, photographs, literature, and mass media offer significant insights into the long-term impact of deindustrialization on individuals and communities that cannot be gleaned from other, more traditional, sources. The afterward, by Steven High, is an insightful evaluation of deindustrialization studies and the ways this special section demonstrates the benefits of novel methodologies and source materials. High also proposes further directions for scholarship, noting, for example, that "nobody speaks to the deindustrialization of large metropolitan cities such as New York, London, or Montreal," and wondering whether the "break with the industrial past may ... be greatest where the outward signs of industrial ruination are least visible."

As a group, these papers critique the earlier generation of deindustrialization studies by noting that while the working classes indeed suffered many defeats, especially recently, people continue to struggle for control over the memory and interpretation of the events and experiences that shaped their lives and their communities. These frontiers of struggle are clearly visible through the cultural prism that these papers bring to the project. Two of the essays, by Phillips and Perchard, focus on the Scottish coal miners who, despite their legendary militancy, were unable to prevent the Thatcher-era pit closures, but have now channeled their anger into political critique and action around Scottish autonomy. Strangleman analyzes deindustrial photography or "ruin porn," while Linkon critiques literary treatments of the long-term impact of the crisis as expressed by writers who are the children and grandchildren of factory workers. Rhodes describes how the rise and fall of Youngstown, Ohio's former middle-weight boxing champion, Kelly Pavlik, has provided local residents with a metaphor for their differing interpretations of the city's decline. Finally, Davies' piece combines photography and text in an anthropological investigation of what is, perhaps, the ultimate example of twentieth century deindustrialization - the Chernobyl nuclear accident and life in and around Chernobyl for those who survived or were born after the disaster.

As we went to press, Americans received the news that Detroit, Michigan, had declared bankruptcy-the ultimate humiliation of the city that came to symbolize the US automobile industry - making this issue's focus on deindustrialization tragically immediate. And while the trajectory of the US auto industry's decline was rooted in the $1950 \mathrm{~s}$, we still remember that cultural resurgence, in the midst of imminent "doom," of the agency and creative spirit of the city's African-American population. African-American auto workers formed progressive associations such as the League of Revolutionary Black Workers (in June, 1969). This is also the same Detroit of Berry Gordy's "Motown" which gave the world a bevy of working-class musical artists who wrote and performed 
the theme songs adopted by a generation facing shrinking employment opportunities and the declining prominence of the US globally. Their songs infused a period of industrial decline with excitement, hope, optimism and a spirit of resistance. Detroit's bankruptcy and the sheer neglect that destroyed this once vital city makes it even more clear that deindustrialization is not a "neutral" process but a clearly "political" one (as contributor James Phillips points out), in which decisions detrimental to the lives of workers can be made by capital when labor is at its weakest. And, as Steven High mentions, the fact that Michigan is now a "right-to-work" state is almost incomprehensible given its history as birthplace of what was once one of the nation's strongest labor unions, the United Auto Workers.

Our second, thematic section, although shorter, is equally exciting and pertinent. Like "Crumbling Cultures" section, this collection of pieces on the Iranian oil industry challenges conventional narratives, in this case about the history of collective action among oil workers. ILWCH is excited that Touraj Atabaki, a member of our Board of Consulting Editors, has brought us this selection of papers, which emerged from his work as head of the Middle East and Central Asia Desk of the International Institute of Social History. The papers grew out of a research project that he directs at the Institute: "The Social History of Labour in the Iranian Oil Industry, 1908-2008." This project, a history "from below," studies the industry from the workers' perspective, focusing on the composition, formation and migration of labor, as well as the living conditions and political engagements of workers both within and outside of company towns. As a group, the three papers are an overview of the social history of oil production in Iran over the course of the twentieth century. Covering different periods, they historicize the gradual integration of a disparate Persia into the Iranian nation-state and the transformation of pastoralists and farmers into workers in a sector-oil-that was so crucial to the further industrial development of the West. These articles document the process through which the companies transformed into large, multinational conglomerates and the impact this process had on the consolidation of Iranian "tribes" and reorganization of provincial polities into a modern nation-state. The industrial behemoth-the inaugural Anglo-Persian/Iranian Oil Company (APOC, AIOC), now British Petroleum(BP)-were in the forefront of the evolution of global capital and the development of new, highly concentrated forms of organization that integrated extraction, production and marketing. As Lenin noted in Imperialism, these oil companies represented the merger of finance capital and industrial capital. The papers in this section also give us insight into crucial periods in the history of this industry and describe how oil revenues allow political visionaries to create a strong, centralized state.

Atabaki's introduction covers the historical context of an emerging oil industry, the evolution of the Iranian state and the activism of the oil workers. Each of the papers offer a critical challenge to the conventional histories of oil workers during the twentieth century. Labor historians can look forward to a future revisionist literature emerging from this exciting research project. 
Atabaki's essay, on the initial period from 1908, explains the transformation of pastoralists into workers. Jefroudi uncovers unique forms of worker protest during the "White Revolution," the period of reform and repression following the 1953 CIA-M16 coup d'état. Jafari, using the records of Savaak (the Iranian secret police), explains the role of oil workers in the Revolution of 1978-79. As a group, these papers reinvigorate the study of both the Iranian Revolution and of workers in this important industry. And finally, the section includes an amazing collection of vintage photographs that span the period of the essays. Several are reproduced in the printed volume but be sure to see the on-line version for additional ones.

This issue also includes several other contributions. Mark Edele's essay on the response of the Soviet people to the German invasion during the Second World War, reviews a group of books, largely published since 2000, that mark a departure from an earlier, conflicting historiography that claims, on one side, that during the 1941 German invasion most Soviet people abandoned the Stalinist regime and, on the other side, that they took up arms en masse in a patriotic fight to defend the Soviet state. The recent studies reviewed draw on cultural, social, and gender history, and reflect a careful statistical analysis of the social composition, ethnicity and gender of both partisans and opponents. For Edele, these studies break through a stalemate, recognizing that both positions can be empirically supported, but only a small fraction of Soviet citizens fell into either camp.

The free-standing article by Jennifer Miller is also a critique of a conventional historical interpretation - in this case, one that credits female German workers, influenced by the feminist surge of the 1970s, with launching the first movement against a system of discriminatory pay. Miller, on the contrary, argues that the attack on unequal pay based on gender was launched by foreign/immigrant women workers despite the opposition of male-led German unions and the discriminatory attacks by Germans of both sexes. The article chronicles the evolution of a sophisticated political consciousness among foreign "guest workers," both male and female, which informed a wave of strikes in the 1970s when Germany's unprecedented economic growth sputtered to a halt. It traces the history of postwar immigrant labor activism and the tortuous attempts of Mediterranean (Greek, Spanish, Serbo-Croatian, Italian and Turkish) migrant workers to achieve solidarity with their German counterparts. At the forefront of this period of unrest was a series of immigrant-led "women's strikes" that, despite union opposition, deportations and police violence, successfully won improved work conditions and employer-provided housing, as well as removing the discriminatory wage system. Their gains, Miller argues, benefitted all workers and demonstrated that the "foreigners" were developing self-identities as "German" and not "guest" workers. This study of the intersection of immigrant and native activism in Europe offers compelling evidence that challenges national labor historiographies to incorporate foreign workers, particularly as they themselves began to identify as members of the polity in which they resided. 
The issue concludes with a continuing "Scholarly Controversy" and two "Reports from the Field." ILWCH Associate Editor Marcel van der Linden responds to the critiques of his essay on the meaning and significance of "Global Labor History" (van der Linden's piece and the critical responses practitioners of Latin American, U.S., European, African, South Asian, and women's labor history appeared in $I L W C H$ 82). We invite readers to continue the discussion/debate by addressing their own responses to our managing editor at ilwch@esc.edu for posting on the Cambridge web site.

"Reports from the Field" features two contributions that give brief, but informative, reports on current developments in labor history, on the one hand, and the experience of labor on the other. One, by Paulo Fontes, summarizes the activities of the Eleventh Conference of Mundos do Trabalho (Worlds of Labor), an annual meeting of labor scholars in Brazil. The second report, by Jeremy Morris, discusses what the author has learned from ten years of interviewing and observing Russian "blue collar" workers who have chosen to reject jobs in the numerous foreign-owned factories that were established in the former Soviet Union after the fall of communism. Many of these manual laborers prefer to eke out a living in the informal economy, which makes it possible for them to nurture personal relationships and retain a degree of personal dignity while also achieving some autonomy from the increasingly regulated work regime imposed by foreign capital.

Our next issue, ILWCH 85, edited by Kate Brown and Thomas Miller Klubock of the journal's Editorial Board, will focus on labor and the environment and include articles on Brazil, Colombia, Egypt, and the US, as well as several pieces with transnational foci. ILWCH 86 will be our first issue focused on African labor history, a field that is also experiencing exciting revisions and organizational initiatives.

And finally we urge all of you to visit our on line section that complements the printed issue.

Carolyn Brown, Jennifer Klein, and Prasannan Parthasarathi 